\title{
Study on Friction Welding of Aluminium based Composites using Desirability Analysis
}

\author{
1R.Adalarasan and ${ }^{2}$ M.Santhanakumar \\ ${ }^{1}$ Research Scholar, Anna University, Chennai-600025, India \\ 2Department of Mechanical Engineering, Saveetha Engineering College, Chennai-602105, India \\ Email: adalno1@yahoo.co.in
}

\begin{abstract}
Friction welding is a solid state joining process with many industrial applications. The welding parameters like upset pressure, frictional pressure and rotational speed play a vital role in determining the responses of the process. The objective of present work is to join aluminium based composite rods using friction welding for various combinations of the input parameters designed by using a L8 orthogonal array. Tensile strength and hardness of the joints formed were observed as the responses for the different trials. Desirability analysis was employed for obtaining the optimal setting of input parameters and ANOVA was performed to predict the contribution of various parameters in affecting the desired responses.
\end{abstract}

Keywords: Friction welding; Al/SiCp composites; Grey relational analysis; optimization.

\section{INTRODUCTION}

Metal Matrix Composites have found their applications in drive shafts, axles and drill bits [1]. Friction welding (FW) is a solid state joining process in which a joint is produced by the heat obtained from rubbing action between surfaces. An additional pressure is applied to obtain coalescence [2]. Joining aluminium alloys using conventional fusion welding process produces negative metallurgical changes such as grain boundary corrosion and a wider Heat affected zone (HAZ). The advantages of FW include an improved machinability, little HAZ and good dimensional tolerances. FW of aluminium bars has revealed the importance of parameters like speed and frictional pressure $[3,4,5]$.

Optimizations using statistical technique generally converge to a local optimum [6] as traditional optimization techniques are calculus based. Many methods were suggested to solve optimization problems including Grey relational analysis (GRA), Regression analysis, principal component analysis (PCA), goal-programming approach and fuzzy logic [7]. A VIKOR method was used to solve the multi response problems compromises on the ranks used for multi criteria decision making [8]. A new approach for the optimization based on orthogonal array with grey theory is bound to take the advantages of both the Taguchi method and the GRA [9]. Experimental design and subsequent optimization using GRA coupled with PCA simplifies the solution for multiple performance characteristics [10]. The option of performing PCA is available in SAS, SPSS and STATISTICA Software [11].

From the literature review, it is understood that little work has been done on FW involving metal matrix composites and hence the work is focussed towards obtaining joints with $\mathrm{Al} / \mathrm{SiCp}$ composites and applying desirability analysis to predict the optimal input conditions.

\section{EXPERIMENTAL DESIGN AND OBSERVATION.}

The matrix material used is Al 6061 aluminium alloy and it is reinforced with fine particles of $\mathrm{SiC}(10 \%$ weight fraction) by the process of stir casting. The cast rods were machined on a lathe to bring the length and diameter to $60 \mathrm{~mm}$ and $10 \mathrm{~mm}$ respectively. The Al/SiCp rods were subjected to solid state joining by using a continuous drive FW machine. The various parameters selected for the study were the upset pressure (U), frictional pressure $(F)$ and rotational speed (S). Two levels were chosen for the various parameters and a $L 8$ orthogonal array was used to conduct the experiments for different combinations of the parameters. The tensile strength $(T)$ of the joints and Vickers hardness $(H)$ were measured as the responses. The layout of FW machine is 
shown in Fig. 1. The response observed during the trials is shown in Table 1.

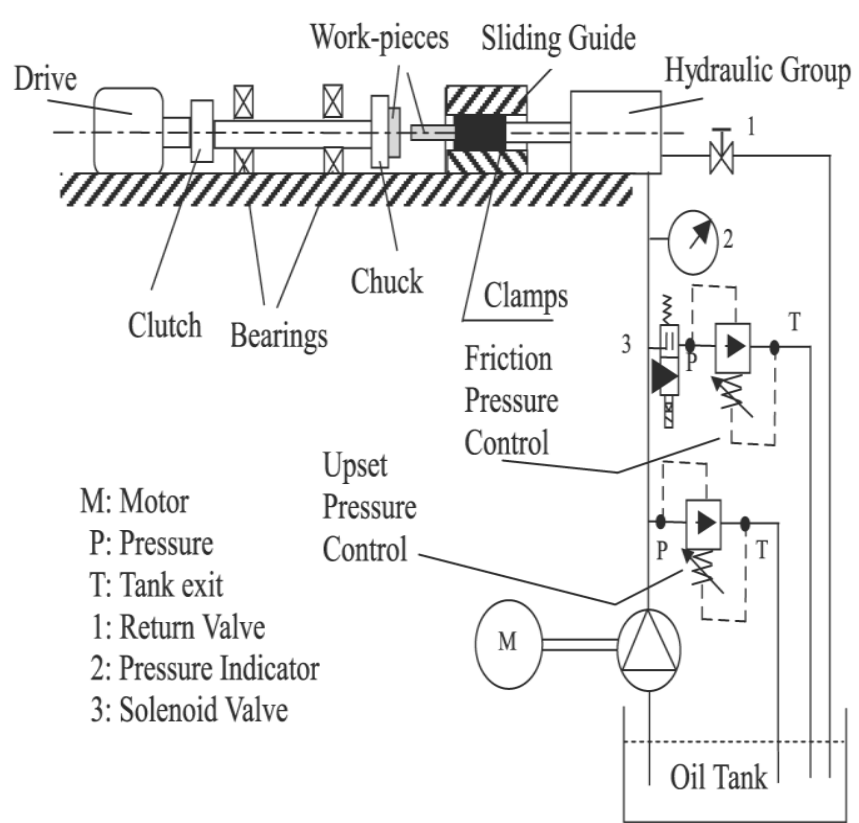

Fig. 1 Friction welding machine layout

Table 1. Responses observed during the different trials

\begin{tabular}{|c|c|c|c|c|c|}
\hline \multirow{2}{*}{ Trial } & \multicolumn{3}{|c|}{ Parameters } & \multicolumn{2}{c|}{ Response } \\
\cline { 2 - 6 } & $\mathrm{U}$ & $\mathrm{F}$ & $\mathrm{S}$ & $\mathrm{TS}$ & $\mathrm{H}$ \\
\hline 1 & 100 & 40 & 1500 & 106.26 & 70.3 \\
\hline 2 & 100 & 40 & 2000 & 93.73 & 76 \\
\hline 3 & 120 & 60 & 1500 & 100.12 & 68.5 \\
\hline 4 & 120 & 60 & 2000 & 80.24 & 79 \\
\hline 5 & 100 & 60 & 1500 & 70.89 & 74.1 \\
\hline 6 & 100 & 60 & 2000 & 74.36 & 65.7 \\
\hline 7 & 120 & 40 & 1500 & 95.15 & 84.4 \\
\hline 8 & 120 & 40 & 2000 & 118.71 & 81.6 \\
\hline
\end{tabular}

\section{MULTI RESPONSE OPTIMIZATION USING DESIRABILITY ANALYSIS}

The desirability function approach is a ranking technique which converts the response into scale free value and the composite desirability index is used to measure the performance. The steps involved in desirability analysis are described below.

Step 1: Calculate the individual desirability (dij) value for (larger the better type) response using the Eq. 1.

$$
d_{i j}=\left(\frac{y_{i j}-L_{i}}{T_{i}-L_{i}}\right)^{s} \text {, if } L_{i} \leq y_{i j} \leq T_{i}
$$

Where $\mathrm{n}$ is the number of variables; $\mathrm{m}$ is the number of trials; $i=1,2 \ldots n$ and $j=1,2 \ldots m$;

$\mathrm{Li}$ and $\mathrm{Ti}$ are the lower and target values of the responses respectively.

Step 2: Calculate the composite grey desirability index (CGDI) by taking the geometric mean of individual desirability values using the Eq. 7 . The CGDI values lies between 0 and 1.

$$
C G D I_{j}=\left\{\prod_{i=1}^{n} d_{i j}\right\}^{\frac{1}{n}} .
$$

Step 3: Identify the optimal level of the parameters based on the CDI value. The quality of product is better at higher value of $\mathrm{CDI}$.

Step 4: Perform ANOVA to identify the contribution of various parameters in affecting the desired responses.

Table 2. Grey relational coefficient and CDI values

\begin{tabular}{|c|c|c|c|}
\hline \multirow{2}{*}{ Trial } & \multicolumn{2}{|c|}{ Individual Desirability } & \multirow{2}{*}{ CDI } \\
\cline { 2 - 3 } & TS & H & \\
\hline 1 & 0.552 & 0.104 & 0.239 \\
\hline 2 & 0.356 & 0.233 & 0.288 \\
\hline 3 & 0.456 & 0.063 & 0.170 \\
\hline 4 & 0.146 & 0.300 & 0.209 \\
\hline 5 & 0.000 & 0.190 & 0.000 \\
\hline 6 & 0.054 & 0.000 & 0.000 \\
\hline 7 & 0.378 & 0.422 & 0.400 \\
\hline 8 & 0.746 & 0.359 & 0.517 \\
\hline
\end{tabular}

\section{RESULTS AND DISCUSSION}

\section{A. Implementation of Desirability analysis.}

The technique of desirability analysis was implemented for the multi-input multi-output process of friction welding. The individual desirability values were 
calculated for the responses and the calculated values of CDI are listed in Table 2. The CDI values are taken as the single representatives of both the responses. Trials with higher values of $\mathrm{CDI}$ represent an operating condition close to the optimal setting of parameters. The $\mathrm{CDI}$ values plotted for the various trials are shown in Fig.

2.

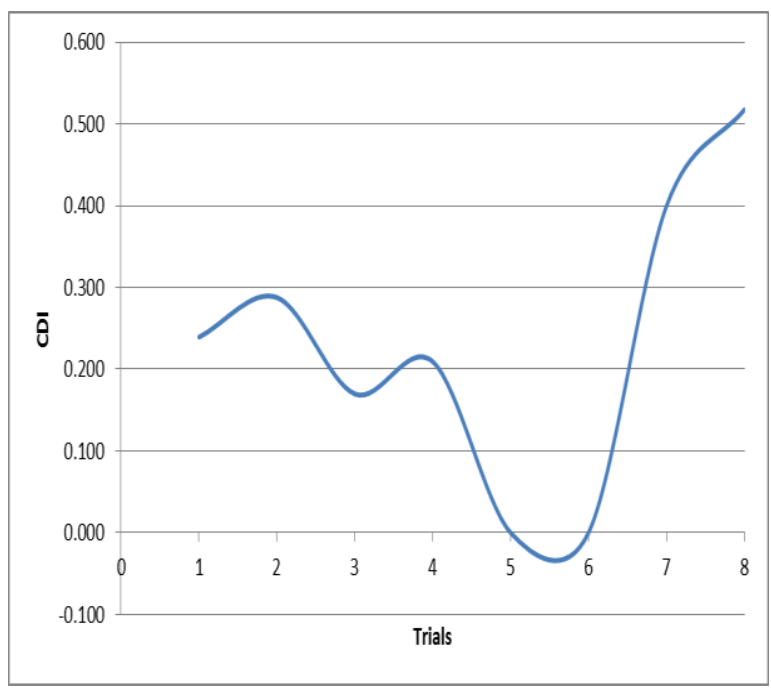

Fig. 2 Plot of $\mathrm{CDI}$ values for various trials

\section{B. Optimal Level Selection and ANOVA.}

The main effect of the parameters on the CDI was calculated for each level and shown in Table 3. The best level of each factor is identified as the one with the maximum value of $\mathrm{CDI}$. The optimal parameter level was found out as U2F1S2. The results of ANOVA on CDI are shown in Table 4. The ANOVA table can be used to categorize the contribution of the various process parameters in affecting the responses. The contribution chart shown in Fig. 3 gives the share of each parameter in affecting the responses.

Table 3. Main effect of parameters on CDI

\begin{tabular}{|c|c|c|c|}
\hline Parameters & Level 1 & Level 2 & Max-Min \\
\hline U & 0.1317 & $\mathbf{0 . 3 2 4 0}$ & 0.1922 \\
\hline F & $\mathbf{0 . 3 6 1 0}$ & 0.0947 & 0.2663 \\
\hline S & 0.2021 & $\mathbf{0 . 2 5 3 6}$ & 0.0514 \\
\hline
\end{tabular}

Table 4. Results of the pooled ANOVA on CDI

\begin{tabular}{|c|c|c|c|c|c|}
\hline $\begin{array}{c}\text { Source } \\
\text { of } \\
\text { varianc } \\
\mathrm{e}\end{array}$ & $\begin{array}{c}\text { Sum of } \\
\text { square } \\
\mathrm{s}\end{array}$ & $\begin{array}{c}\text { Degree } \\
\text { s of } \\
\text { freedo } \\
\mathrm{m}\end{array}$ & $\begin{array}{c}\text { Mean } \\
\text { sum } \\
\text { of } \\
\text { square }\end{array}$ & $\begin{array}{c}\mathrm{F}- \\
\text { ratio }\end{array}$ & $\begin{array}{c}\% \\
\text { Contributio } \\
\mathrm{n}\end{array}$ \\
\hline $\mathrm{V}$ & 0.0739 & 2 & $\begin{array}{c}0.036 \\
9\end{array}$ & $\begin{array}{c}20.46 \\
2\end{array}$ & 32.8993 \\
\hline $\mathrm{C}$ & 0.1418 & 2 & $\begin{array}{c}0.070 \\
0\end{array}$ & 39.27 & 63.1386 \\
\hline $\mathrm{S}$ & 0.0052 & 2 & $\begin{array}{c}0.002 \\
6\end{array}$ & $\begin{array}{c}1.464 \\
3\end{array}$ & 2.3542 \\
\hline Error & 0.0036 & 2 & $\begin{array}{c}0.001 \\
8\end{array}$ & & 1.6078 \\
\hline Total & 0.2246 & 8 & & & 100 \\
\hline
\end{tabular}

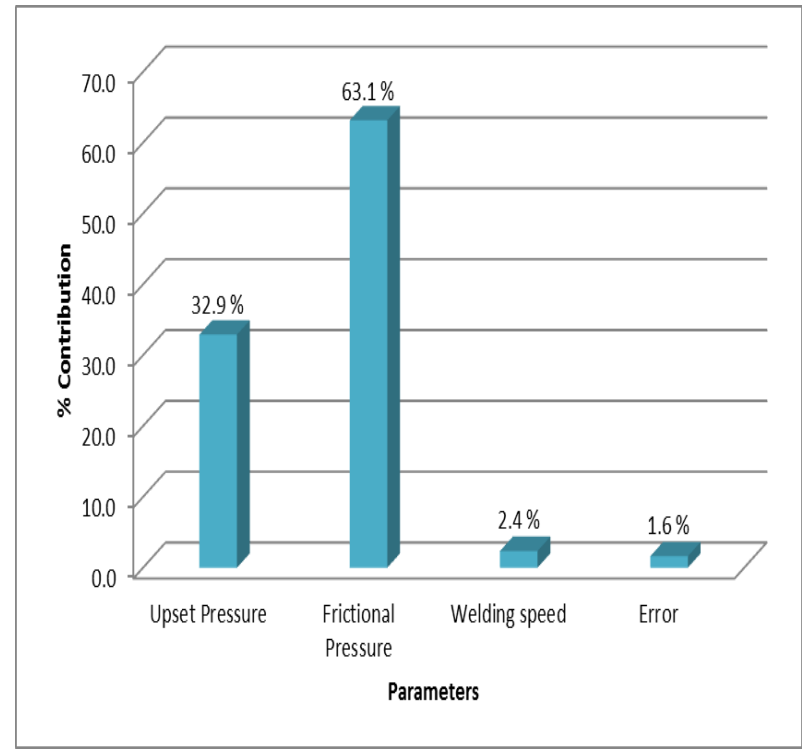

Fig. 3 Contribution chart

\section{CONCLUSION}

This paper has presented a report on the effectiveness of friction welding process in handling Al/SiCp composites. The following conclusions can be drawn.

- The ranking capabilities of desirability method were used to predict the optimal setting of parameters as frictional pressure: Frictional pressure: $40 \mathrm{MPa}$, upset pressure: $120 \mathrm{MPa}$ and speed: 2000 rpm.

- The ANOVA results have shown that upset pressure is the primary parameter influencing the responses with a contribution of $63.1 \%$. 


\section{REFERENCES}

[1.] T.W.Clyne and P.J.Withers(1999): An Introduction to Metal matrix composites, Cambridge university press,Cambridge

[2.] Maaklekian.M (2007),"Friction welding - Critical assessment of literature", International journal of Science and Technology of Welding and Joining, Vol.12, pp. 738-759

[3.] P. Sathiya, S. Aravindan and A. Noorul Haq(2004) " Friction Welding Of Austenitic Stainless Steel And Optimization Of Weld Quality". International Symposium of Research Students on Materials Science and Engineering December 20-22, Chennai, India.

[4.] Biljiana Savic, Svetislav Marcovic, and Radovan Ciric (2008)"Physical Model of the friction welded joint of different types of Steel", ME Transactions, Vol.36, pp 9397.

[5.] D.Ananthapadmanaban, V. Seshagiri Rao, K. Prasad Rao(2009) "A study of mechanical properties of friction welded mild steel to stainless steel joints" Mater Des; 26 : $42-46$.

[6.] Koichi Ogawa, Hiroshi Yamaguchi, Seiichi Kaga and Kazuhiko Sagaguchi(2003),"Optimization of Friction Welding Condition for S45C Carbon Steel Using Statistical Technique", Transactions of the Japan Welding Society, Vol 24, № 2,pp. 47.
[7.] K.Krishnaiah ,P.Shahabudeen ,R.Jeyapaul(2005) "Quality management research by considering multi-response problems in the Taguchi method- a review"., International Journal of Advanced Manufacturing Technology, Vol. 26, , pp.1331-1337.

[8.] Lee-Ing Tong . Chi-Chan Chen . Chung-Ho Wang(2007) "Optimization of multi-response processes using the VIKOR method" , International Journal of Advanced Manufacturing Technology, Vol. 31,pp. 1049-1057.

[9.] A.Noorul Haq, P.Marimuthu, R.Jeyapaul.,(2007) "Multi response optimization of machining parameters of drilling $\mathrm{Al} / \mathrm{SiC}$ metal matrix composite using Grey Relational Analysis in the Taguchi method", International Journal of Advanced Manufacturing Technology,DOI 10.1007/s00170-007-0981-4.

[10.] Arshad Noor Siddiquee, Zahid A. Khan, Zulquernain Mallick.(2010), "Grey Relational Analysis coupled with Principal Component Analysis for Optimization Design of the Process Parameters in In-feed Centre less Cylindrical Grinding " , International Journal of Advanced Manufacturing Technology, Vol. 46, pp. 983-992.

[11.] Susanta Kumar Gauri, Shankar Chakraborthy (2009), "Optimization of Multiple Responses for WEDM Processes using Weighted Principal Components ", International Journal of Advanced Manufacturing Technology, Vol. 40, pp. $1102-1110$. 